\title{
Evaluation of Different Industrial End Uses of Improved Cassava Varieties Grown in South-Eastern Africa
}

\author{
Gilbert O. Sampson, Emmanuel O. Afoakwa, Leon Brimer, Drinah Nyirenda, \\ Cornelius Nkonkola Mwansa, and Linley Chiwona-Karltun
}

\section{ABSTRACT}

\begin{abstract}
This work characterized two local and seven improved Cassava Mosaic Disease [CMD]-tolerant cassava varieties for their biochemical composition and viscoelastic (pasting) properties. The biochemical composition and starch pasting properties were evaluated respectively using standard analytical methods and Brabender Viscoamylograph. Cluster dendogram and principal component analyses compared similarities in the nine cassava varieties, thus predicting their varied food and industrial end uses. The different cassava varieties had starch, total sugars and reducing sugars content ranging from 53-69\%, $6.5-9.2 \%$ and $0.9-2.5 \%$, respectively. The starch content of the cassava varieties on dry weight basis (DW) varied from $54.0 \%$ to $69.0 \%$ with Nalumino having the lowest and Mweru having the highest respectively. Tanganyika, Mweulu, and Banguerlu also recorded relatively higher starch content of $62.7 \%, 63.6 \%$ and $63.6 \%$ respectively. Mweru, Tangayoka, Mweulu, and Bangweulu had fairly high starch content $(>60 \%)$ and thus could be used for many commercial products such as starches, alcohols and glucose. The viscoelastic properties of the different varieties had pasting temperature $\left(63.5-67.6^{\circ} \mathrm{C}\right)$, peak viscosity $(402-595$ $\mathrm{BU})$, viscosity at $9^{\circ} \mathrm{C}(394-592 \mathrm{BU})$, viscosity at $50^{\circ} \mathrm{C}(126-254)$, breakdown viscosity (236-352 BU) and setback (-100-4 BU). Tanganyika recorded the highest pasting temperature $\left(67.6^{\circ} \mathrm{C}\right)$, peak viscosity $(595 \mathrm{BU})$, viscosity at $9^{\circ} \mathrm{C}(592 \mathrm{BU})$ and viscosity at $9^{\circ} \mathrm{C}$-hold $(317 \mathrm{BU})$. Bangweulu, Mweulu, Mweru, Manyokola, Nalumino, Kampolombo and Chila A were clustered differently from Chila B and Tanganyika on the basis of their biochemical qualities and pasting properties. These characterizations showed that Tanganyika would be suitable for products requiring high elasticity and gel strength, easier to cook and also more stable during cooking/preparation such as fufu (pounded cassava) and banku or Nshima. Chila A would also be suitable for use as fillers and binders in the baking, confectionery industries as substitutes of wheat flour. The low viscosities of Chila $B$ make it suitable for household food uses such as snacks where the roots are boiled, roasted or toasted and consumed.
\end{abstract}

Keywords: Cassava, processing, pasting characteristic, starch quality, variety.
Submitted : November 22, 2021

Published : January 11, 2022

ISSN: $2684-1827$

DOI: 10.24018 /ejfood.2022.4.1.419

\section{G. O. Sampson*}

Faculty of Vocational Education, AAM University of Skills Training and Entrepreneurial Development, Kumasi, Ghana.

(e-mail: gosampson@ ${ }^{\circledR}$ uew.edu.gh)

E. O. Afoakwa

Ghana Communication Technology

University, Accra, Ghana.

(e-mail: eoafoakwa@ ${ }^{\circledR m a i l . c o m) ~}$

L. Brimer

Department of Veterinary Disease Biology, Copenhagen, Denmark University of Copenhagen, Denmark.

D. Nyirenda

Department of Animal Science, University of Zambia, Lusaka, Zambia.

C. N. Mwansa

Department of Animal Science, University of Zambia, Lusaka, Zambia.

L. Chiwona-Karltum

Department of Urban \& Rural Development, Swedish University of Agricultural Sciences (SLU), Uppsala, Sweden.

*Corresponding Author

\section{INTRODUCTION}

Cassava (Manihot esculenta Crantz) is an important perennial food crop usually found in the tropics [1]. It belongs to the family Euphorbiaceae and serves as an important diet for an about 700 million of the world's population [2]-[4]. Grown predominantly by small-scale farmers with limited resources, the crop is widely utilized as staple food and animal feed with a total cultivated area of over 26 million ha [5]-[7]. The importance of cassava to the livelihoods and socio-economic development of many millions of poor people has made the commodity a target for food and nutrition interventions in many developing countries [8]-[13]. Due to its versatility of utilization, total global utilization of cassava is estimated to increase from 230 to 275 million tonnes between 2010 and 2020, making cassava utilization in Africa equivalent to $62 \%$ of total quantities of global production [14], [15].
Nutritionally, cassava roots are an important source of carbohydrate for humans and animals, having a higher energy density $(610 \mathrm{~kJ} / 100 \mathrm{~g}$ fresh weight than other root and tuber crops such as sweet potatoes $(460 \mathrm{~kJ} / 100 \mathrm{~g})$ and taro $(490$ $\mathrm{kJ} / 100 \mathrm{~g}$ ) [2], [13], [16], [17]. Raw cassava root has more carbohydrate than potatoes but less carbohydrate than wheat, rice, yellow corn, and sorghum on a $100 \mathrm{~g}$ basis $[11,18]$. The pattern of cassava utilization varies greatly across the various intra and inter-continental boundaries. However, it is utilized primarily as the major staple [19] in the largest part of the developing world mainly Africa and the south-east Asia.

Viscoelastic properties of starchy foods are widely used to assess the gel strengths of different starches and their gelatinization properties [20], [21]. An important processing quality of cassava starch is its ability to gelatinize, forming thick pastes suitable for human consumption. This property is mainly found in cereals and root crops [22]. Pasting characteristics of starches is essential in determining the 
industrial applications of the starches [23]. A wide pallet of applications in the food industry is open to cassava flour. For use as binders, fillers and thickeners, the paste formed should not retrograde and should be stable whether cold or hot [24]. Cassava varieties providing flours with these characteristics may be used as thickeners, and in the bakery industry for bread and pastries such as cakes and biscuits. Again, attaining gelatinization at a lower temperature has been reported to improve bread-making quality [25], whiles high peak viscosity and stability (or low breakdown viscosity) of cassava flour gives acceptable bread [26]. Non-cohesive pastes are normally seen for flours//starches with a low setback value [27]. Such starches cannot be used for products requiring good stability at low temperatures, e.g., products for refrigeration [2].

Varietal variation in cassava plays a very important role in the production of diversified food products due to its inherent biochemical characteristics such as starch content, sugar content and pasting characteristics [28]. Biochemical composition and starch pasting properties of cassava are among the most important parameters used to predict the suitability of flours and starches for certain end product uses, and aid the selection of an appropriate variety for use in various food and industrial applications. This study was therefore aimed at characterizing the nine different cassava varieties (Bangweulu, Nalumino, Mweru, Chila A, Chila B, Tanganyika, Kampolombo, Mweulu, and Manyokola) produced within South-eastern Africa for their food and industrial end uses based on their varied biochemical composition and starch pasting properties.

\section{MATERIALS AND METHODS}

\section{A. Cassava Varieties}

Two local and seven improved CMD-tolerant cassava varieties were obtained from the farmers' fields in the Chisamba Community located within the Chongwe District in Zambia. These were: Kampolombo, Bangweulu, Chila $A$ and Chila B, Mweru, Mweulu, Tanganyika, Nalumino and Manyokola. Out of these the two varieties, Mweulu and Tanganyika were local. The improved varieties were a result of the cassava breeding programme released varieties by the Zambian Agricultural Research Institute (ZARI) [12].

\section{B. Preparation of Flours for Sugars and Viscoelastic Analysis}

Root were harvested and transported to the laboratory within three hours of harvest. At the laboratory, the root samples were cleaned, peeled, and washed with room temperature water. Parts of the parenchyma from the different sections of the peeled tubers were cut into cubes and oven dried at $60^{\circ} \mathrm{C}$ for $48 \mathrm{hrs}$. The dry cubes were ground into flour to pass through a $250-\mu \mathrm{m}$ sieve by means of a Hammer mill (Christy and Norris Ltd., Model 2A, Chelmsford, Surrey, UK). The flour samples obtained were then packaged into polypropylene bags and kept at room temperature $\left(25^{\circ} \mathrm{C}\right)$ for analyses. Duplicate samples were prepared for each variety and triplicate analyses were conducted on each of the replicates. The mean values of all the analyses conducted and standard deviations were reported.

\section{Starch Extraction and Analysis}

The starch was extracted from the nine varieties by sedimentation method [9]. The tubers were sorted out and washed with clean water. The tubers were peeled, washed, with clean water to remove all the dirt and grated into chunks of about $0.5-1 \mathrm{~mm}$ thick. The $400 \mathrm{~g}$ of the samples were weighed and milled with $800 \mathrm{ml}$ of water using blender (Philips 8010G, Chicago, IL, USA). The slurry was filtered through cheese cloth. The retained solids were washed with $4000 \mathrm{ml}$ of water and filtered again until little or no starch was found in the residue. The filtrate was allowed to sediment overnight and the starch obtained was dried under room temperature until completely dry. The dried starch was weighed and expressed as a percentage of dry weight.

The total, reducing and non-reducing sugars were determined using the methods outlined by Lane and Eynon [29].

\section{Determination of Viscoelastic Properties and Pasting Characteristics}

The determination of the viscoelastic properties and the pasting characteristics were done using Brabender ViscoAmylograph (Model No. 802525, Duisburg, Germany) as outlined by Afoakwa et al. [24].

\section{E. Data Analysis}

Data analysis and graphical presentation were done using Minitab (version 14) and Microsoft Excel (2007 version) respectively. Cluster and principal component analysis (PCA) were performed to establish similarities and investigate the relationships among the various studied indices and the cassava samples

\section{RESULTS}

\section{A. Biochemical Composition of Cassava Varieties}

Table I presents the parenchyma starch content and the sugar composition of the flour from the various cassava varieties studied. The starch content of the cassava varieties on dry weight basis (DW) varied from $54.0 \%$ to $69.0 \%$ with Nalumino having the lowest and Mweru having the highest respectively. Tanganyika, Mweulu, and Banguerlu also recorded relatively higher starch content of $62.7 \%, 63.6 \%$ and $63.6 \%$ respectively. Total sugars ranged from $6.5 \%$ (Bangweulu) to $9.2 \%$ (Nalumino). The results also indicated that Nalumino which recorded the highest total sugar content $(9.2 \%)$ recorded the least starch content $(53 \%)$. The reducing sugar content was observed to range from $0.94 \%$ (Chila A) to $2.5 \%$ (Kampolombo). Non-reducing sugars formed the major component of the total sugars of the cassava varieties. It varied from $4.8 \%$ to $7.5 \%$ with Bangweulu being the lowest and Nalumino the highest.

\section{B. Pasting Temperature}

Table II gives the viscoelastic properties of all the cassava varieties studied. The pasting temperature ranged from $63.5^{\circ} \mathrm{C}$ to $67.6{ }^{\circ} \mathrm{C}$ with Mweulu recording the least whiles Tangayoka recorded the highest (Table II). Kampolombo and Bangweulu also recorded fairly high pasting temperatures of $66.6{ }^{\circ} \mathrm{C}$ and $65.9{ }^{\circ} \mathrm{C}$, respectively. Chila A and Nalumino recorded the same pasting temperature of $64.2{ }^{\circ} \mathrm{C}$. 
TABLE I: BIOCHEMICAL COMPOSITION OF CASSAVA VARIETIES

\begin{tabular}{|c|c|c|c|c|}
\hline Variety & $\begin{array}{c}\text { Starch } \\
(\%)^{1}\end{array}$ & $\begin{array}{c}\text { Total } \\
\text { sugars } \\
(\%)^{2}\end{array}$ & $\begin{array}{c}\text { Reducing } \\
\text { sugars }^{2} \\
(\%)\end{array}$ & $\begin{array}{c}\text { Non- } \\
\text { reducing } \\
\text { sugars }^{2} \\
(\%)\end{array}$ \\
\hline Mweulu & $63.60 \pm 0.58$ & $8.06 \pm 0.08$ & $1.58 \pm 0.01$ & $6.48 \pm 0.05$ \\
\hline Mweru & $69.01 \pm 0.34$ & $8.32 \pm 0.07$ & $1.81 \pm 0.04$ & $6.51 \pm 0.04$ \\
\hline Chila A & $57.59 \pm 0.42$ & $6.72 \pm 0.03$ & $0.94 \pm 0.01$ & $5.78 \pm 0.08$ \\
\hline Chila B & $57.03 \pm 0.35$ & $7.34 \pm 0.09$ & $1.91 \pm 0.02$ & $5.43 \pm 0.05$ \\
\hline Bangweulu & $63.61 \pm 0.48$ & $6.48 \pm 0.06$ & $1.68 \pm 0.03$ & $4.80 \pm 0.04$ \\
\hline Manyokola & $58.40 \pm 0.63$ & $7.64 \pm 0.01$ & $1.06 \pm 0.02$ & $6.58 \pm 0.05$ \\
\hline Kampolombo & $58.06 \pm 0.85$ & $8.94 \pm 0.08$ & $2.53 \pm 0.02$ & $6.41 \pm 0.07$ \\
\hline Tanganyika & $62.77 \pm 0.86$ & $8.99 \pm 0.04$ & $2.46 \pm 0.01$ & $6.53 \pm 0.03$ \\
\hline Nalumino & $52.99 \pm 0.56$ & $9.20 \pm 0.06$ & $1.68 \pm 0.03$ & $7.52 \pm 0.06$ \\
\hline
\end{tabular}

Values reported on dry weight basis.

1: As isolated from the fresh paranchyma.

2: As analysed in dried, sieved flour.

\section{Peak Viscosity}

Peak viscosities of all the cassava varieties are shown in Table II. Tangayoka gave the highest peak viscosity of 595 BU whiles Chila B recorded the least peak viscosity of 402 BU. ANOVA conducted on the results showed significant differences $(p<0.05)$ in the peak viscosities of the cassava samples. With the exception of Kampolombo and Chila B which recorded peak viscosities of $490 \mathrm{BU}$ and $402 \mathrm{BU}$ respectively, the rest of the cassava varieties recorded peak viscosities above $500 \mathrm{BU}$

\section{Heating Cycle (Viscosity at $95{ }^{\circ} \mathrm{C}$ and Viscosity at $95^{\circ} \mathrm{C}$-hold)}

Viscosity at $95{ }^{\circ} \mathrm{C}$ ranged from 394 BU to 592 BU for all the cassava varieties with Chila B recording the least of 394 BU and Tanganyika recorded the highest of 592 BU. Kampolombo, Manyokola, Chila A, Mweru and Mweulu also recorded fairly high viscosities of above $460 \mathrm{BU}$ at $95^{\circ} \mathrm{C}$. Chila B was observed to produce the least viscosity of 166 BU at $95{ }^{\circ} \mathrm{C}$-hold whiles Tanganyika gave the highest of 317 BU. With the exception of Chila B, Kamplombo and Nalumino which recorded viscosities below 220 BU, the rest of the cassava varieties recorded values above $220 \mathrm{BU}$. This suggest that cassava varieties with high viscosity (>220 BU) at $95^{\circ} \mathrm{C}$-hold experienced little breakdown in starch, thus, may be considered stable.

\section{E. Cooling cycle (Viscosity at $50{ }^{\circ} \mathrm{C}$ and Viscosity at $50{ }^{\circ} \mathrm{C}$-hold)}

Viscosity at $50{ }^{\circ} \mathrm{C}$ ranged from $126-254 \mathrm{BU}$ for all the cassava varieties with Chila B recording the least of $126 \mathrm{BU}$ and Chila A recording the highest of 254 BU. Mweulu, Tanganyika and Bangweulu also recorded fairly high viscosities of above $200 \mathrm{BU}$ at $50^{\circ} \mathrm{C}$. It was observed that the viscosity of the samples at $50^{\circ} \mathrm{C}$-hold was lower than the viscosity at $50{ }^{\circ} \mathrm{C}$ for all the samples except Chila $\mathrm{A}$ and Tanganyika.

\section{F. Breakdown Viscosity and Setback}

Breakdown viscosity ranged from $236 \mathrm{BU}$ (Chila B) to 352 BU (Bangweulu) (Table II). ANOVA results on the data indicated that the differences amongst the varieties were significant $(\mathrm{p}<0.05)$. Breakdown viscosities was significantly higher (>300 BU) in the other cassava varieties studied with the exception of Mweru, Chila B, Kampolombo and Tanganyika which recorded breakdown viscosities below 300 BU. Chila A registered the highest setback value of $4 \mathrm{BU}$ which was significantly different $(p<0.05)$ from the other studied varieties whilst Tangayoka recorded the least setback $(-100 \mathrm{BU})$.

\section{G. Pasting Characteristics of Cassava Varieties}

Fig. 1 shows a typical pasting profile curve (amylogram) generated from Brabender Viscoamylograph. Region A represents the beginning of gelatinization (pasting temperature). Regions $\mathrm{B}, \mathrm{C}$ and $\mathrm{D}$ represent the peak viscosity, viscosities at $95{ }^{\circ} \mathrm{C}$ and $95^{\circ} \mathrm{C}$-hold, respectively. Regions $\mathrm{E}$ and $\mathrm{F}$ show viscosity at $50{ }^{\circ} \mathrm{C}$ and viscosity at $50{ }^{\circ} \mathrm{C}$-hold respectively whiles region B-D represent breakdown viscosity and E-D shows setback. Fig. 2 show amylogram generated from Brabender Viscoamylograph for the cassava varieties studied. A closer look at the amylograms for all the studied cassava varieties (Fig. 2) revealed that the viscosity of all the cassava varieties increased to a peak (peak viscosity) with Tanganyika recording the highest peak viscosity of 595 BU whiles Chila B recorded the least (402 $\mathrm{BU})$. The viscosity of all the cassava paste decreased during the heating cycle $\left(95^{\circ} \mathrm{C}\right.$ and $95{ }^{\circ} \mathrm{C}$-hold).

With an exception for Chila A, the viscosity of the pastes observed for all the cassava varieties decreased remarkedly during the cooling cycle from 95 to $50^{\circ} \mathrm{C}$; as compared to the viscosity of the pastes observed during the heating cycle. The increase in the viscosity of the paste of Chila A sample during the cooling cycle could probably be due to the gelation and swelling of the starch granules [21]. The amylograms also revealed that the viscosity of the samples at $50{ }^{\circ} \mathrm{C}$ hold was lower than the viscosity at $50{ }^{\circ} \mathrm{C}$ for all the samples except Chila A and Tanganyika. A close examination of the pasting characteristics showed that Tanganyika showed higher pasting characteristics. Banguelu and Mweru also showed relatively higher pasting characteristics. Chila B however, showed the least pasting characteristics.

TABLE II: VISCOELASTIC CHARACTERIZATION OF CASSAVA VARIETIES

\begin{tabular}{|c|c|c|c|c|c|c|c|c|}
\hline Variety & $\begin{array}{c}\text { Pasting } \\
\text { temper-ature } \\
\left({ }^{\circ} \mathrm{C}\right)\end{array}$ & $\begin{array}{c}\text { Peak } \\
\text { viscosity } \\
(\mathrm{BU})\end{array}$ & $\begin{array}{c}\text { Viscosity at } \\
95^{\circ} \mathrm{C} \\
(\mathrm{BU})\end{array}$ & $\begin{array}{l}\text { Viscosity at } \\
95^{\circ} \mathrm{C}-\text { Hold } \\
\text { (BU) }\end{array}$ & $\begin{array}{l}\text { Viscosity at } \\
50^{\circ} \mathrm{C}(\mathrm{BU})\end{array}$ & $\begin{array}{l}\text { Viscosity at } \\
50^{\circ} \mathrm{C}-\text { Hold } \\
\text { (BU) }\end{array}$ & $\begin{array}{c}\text { Break } \\
\text { down }(B U)\end{array}$ & $\begin{array}{c}\text { Setback } \\
(\mathrm{BU})\end{array}$ \\
\hline Mweulu & 63.5 & 563 & 485 & 237 & 211 & 193 & 327 & -25 \\
\hline Mweru & 65.0 & 545 & 537 & 258 & 183 & 173 & 286 & -75 \\
\hline Chila A & 64.2 & 558 & 486 & 248 & 254 & 238 & 309 & 4 \\
\hline Chila B & 64.6 & 402 & 394 & 166 & 126 & 106 & 236 & -38 \\
\hline Bangweulu & 65.9 & 593 & 412 & 242 & 205 & 188 & 352 & -36 \\
\hline Manyokola & 64.5 & 554 & 479 & 230 & 168 & 158 & 323 & -62 \\
\hline Kampolombo & 66.6 & 490 & 467 & 219 & 196 & 171 & 271 & -23 \\
\hline Tanganyika & 67.6 & 595 & 592 & 317 & 218 & 219 & 277 & -100 \\
\hline Nalumino & 64.2 & 518 & 441 & 216 & 173 & 155 & 301 & -43 \\
\hline
\end{tabular}




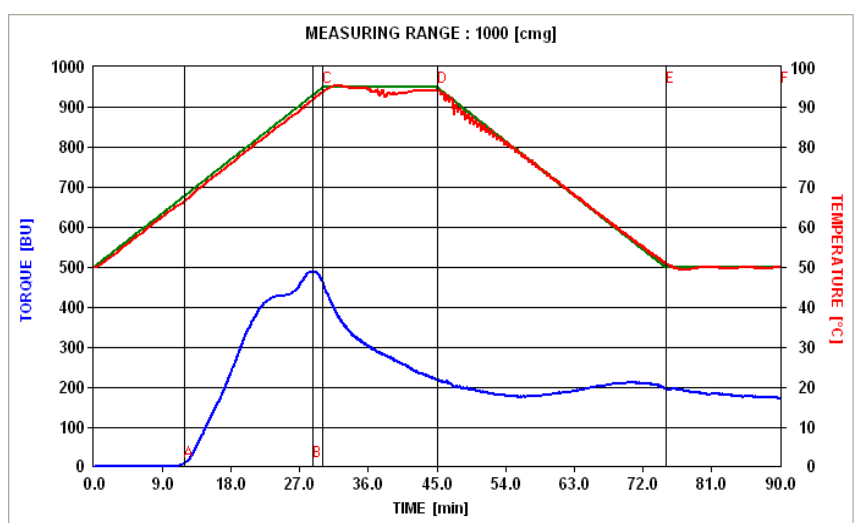

Fig. 1. A typical pasting profile curve (amylogram) from the Brabender Viscoamylograph.

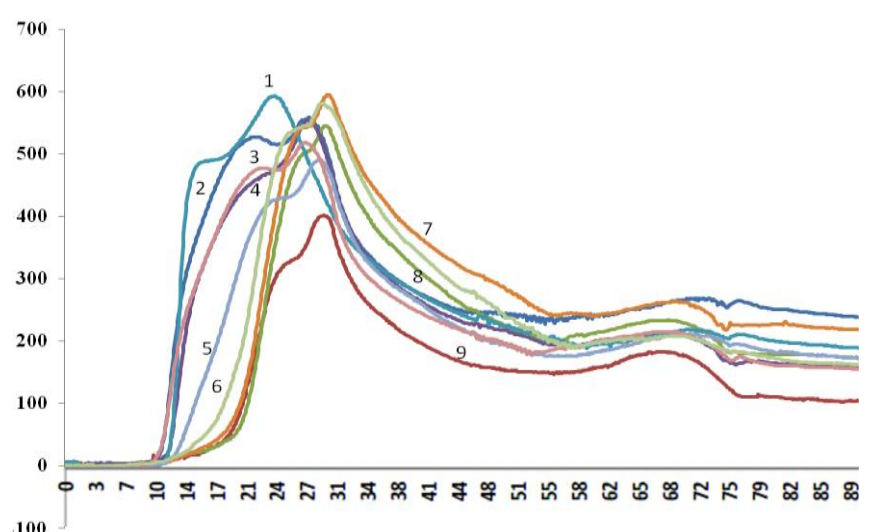

Fig. 2. Amylograms showing the pasting characteristic profiles of the studied cassava varieties.

KEY: 1-Banguelu; 2- Chila A; 3-Nalumino; 4-Mweulu; 5-Kapolombo; 6Manyokola; 7-Tangayoka; 8-Mweru; 9-Chila B.

H. Cluster and Principal Component Analyses for Biochemical Composition and Viscoelastic Properties of Cassava Varieties

Cluster and principal component analyses were applied to the biochemical composition and viscoelastic properties of the cassava samples. This was done by grouping cassava varieties with similar characteristics to display pattern and interrelationship between samples and their chemical characteristics. Fig. 3 shows the cluster observations dendogram for biochemical composition and viscoelastic properties of the cassava varieties. This partitioned the samples into three clusters based on similarity of characteristics. Mweulu, Manyokola, Kampolombo, Nalumino, Chila A, Mweru and Bangweulu formed the first cluster. Chila B and Tanganyika formed the second and third clusters respectively (Fig. 3).

Principal component analysis applied to the biochemical composition and viscoelastic properties of the cassava varieties showed that the two components (PC1 and PC2) explained a variability of $67.5 \%$ in the results. $\mathrm{PC} 1$ alone accounted for $39.0 \%$ of the variation in the results while PC2 explained $28.5 \%$ (Fig. 4). The sample score explained the portioning observed in the cluster analysis. Chila A, Bangweulu, Mweulu, Mweru, and Tanganyika were found loaded to the positive side while Manyokola, Nalumino, Kampolombo and Chila B and were found loaded to the negative side of the PC1. The variable weights plot (Fig. 5) showed a loading of all the biochemical indices (starch, total sugars, reducing sugars and non-reducing sugars) and pasting temperature close to each other on the positive side of the $\mathrm{x}$ axis (PC1) and peak viscosity and setback viscosity loaded on the negative and positive side of $\mathrm{PC} 1$ which are related to the loadings of Tanganyika and Chila B, respectively.

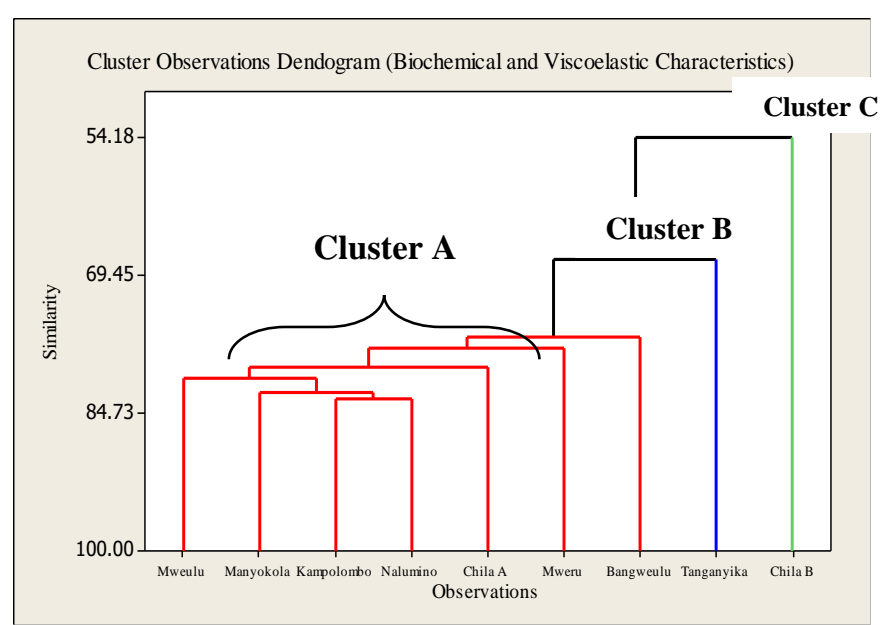

Fig. 3. Cluster observations dendogram for biochemical composition and viscoelastic properties of cassava varieties.

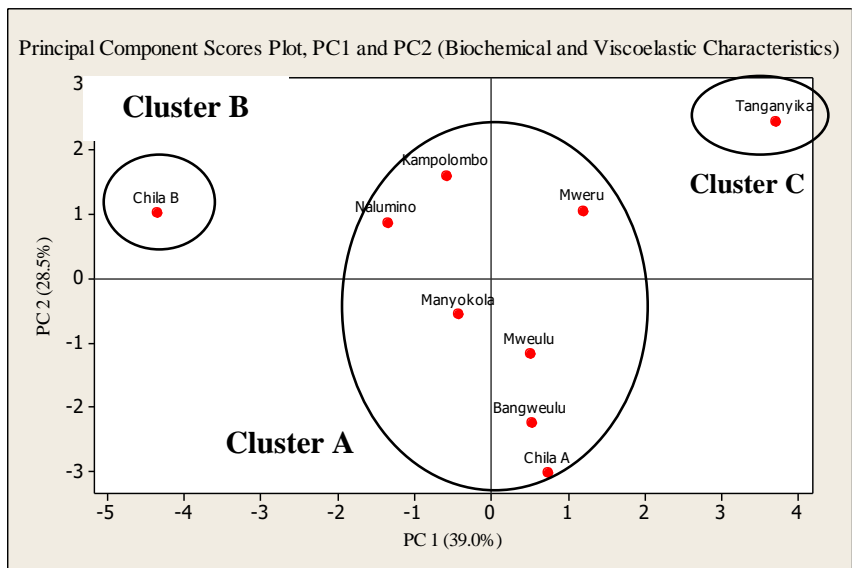

Fig. 4. Sample scores of plots for the principal component analysis of biochemical composition and viscoelastic properties of cassava varieties.

\section{DISCUSSION}

\section{A. Biochemical Composition of Cassava Varieties}

Starch content in cassava is an important determinant of the industrial applications of the cassava variety. The use of starch for industrial food applications has been discussed extensively [2], [11], [30], [31]. Starches are commonly used to thicken liquid foods, such as soups and sauces. Even though the starch content of all the varieties were below the up to $80 \%$ reported by Gil and Buitrago [16], Mweru, Tangayoka, Mweulu, and Bangweulu had fairly high starch content $(>60 \%)$ and thus could be used for many commercial products such as starches, alcohols and glucose. Total sugars content were noted to be similar to previous reported on cassava. Aryee et al. [2] and Padonou et al. [31] reported values from $1.57 \%$ to $7.50 \%$ for study on different cassava genotypes. Similarly, results on reducing sugars were comparable to the value of $1.67 \mathrm{~g} / 100 \mathrm{~g}(1.67 \%)$ reported by Mégnanou et al. [32] from Cote d'Ivoire.

\section{B. Viscoelastic Properties of Cassava Varieties}

The ability of starch to swell and give a viscous paste when an aqueous suspension of the starch granules is heated above 
the gelatinization temperature is one of the most important functional properties of starch [20]. Prolonged heating of the starch granules leads to disintegration of the granules, which brings about significant change in the viscosity and other rheological properties of the paste. The pasting and gelatinization processes form the two most important characteristics which influence the quality and aesthetic values in the food processing industry as they affect texture and digestibility of starch-based foods [9].

Afoakwa et al. [33] explained that the pasting temperature is the point at which the first measurable viscosity is noticed, and it is identified by an abrupt change in the viscosity resulting from swelling of the starch granules. The initiation of gelatinization of the starch granules during heat processing is denoted by the pasting temperature, and this is affected by the starch concentration [34]. A suspension of high starch concentration results in low pasting temperatures and the presence of monosaccharides and oligosaccharides lead to increases in pasting temperatures [35]. Pasting temperatures relate to water binding capacity of starches [9], and a higher pasting temperature implies higher water binding capacity, higher gelatinization, and lower swelling capacity of the starches, and these are caused by the organization of starch granules [36]-[38]. Pasting temperature was significantly $(\mathrm{p}<0.05)$ affected by the cassava varieties (Table III). The high pasting temperature observed suggest that these cassava varieties would have relatively high cooking temperature and time profile compared to Mweulu which recorded the least pasting temperature. The similar pasting properties recorded for Chila A and Nalumino indicates that cooking time for these cassava varieties and their products will be similar. The low pasting temperature recorded by Mweulu, could be attributed to the relatively lower cross bondings in its starch granule [20].

TABLE III: ANOVA SUMMARY SHOWING F-RATIOS OF THE VISCOELASTIC CHARACTERIZATION OF CASSAVA VARIETIES

\begin{tabular}{cc}
\hline Process variables & F-ratios \\
\hline Pasting temperature & $13045.45^{*}$ \\
Peak viscosity & $30705.19^{*}$ \\
Viscosity at $95^{\circ} \mathrm{C}$ & 1.85 \\
Viscosity at $95^{\circ} \mathrm{C}-\mathrm{Hold}$ & $17347.18^{*}$ \\
Viscosity at $50^{\circ} \mathrm{C}$ & $4844.43^{*}$ \\
${\text { Viscosity at } 50^{\circ} \mathrm{C}-\mathrm{Hold}}^{\text {Breakdown }}$ & $9864.50^{*}$ \\
Setback & $4131.53^{*}$ \\
\hline
\end{tabular}

* Significant at $\mathrm{p}<0.05$.

The highest viscosity attained during the heating cycle $\left(25-95^{\circ} \mathrm{C}\right)$ of starch-based foods is the peak viscosity and this is related to the easiness of cooking of the samples being analyzed [33], [38], and it reflects the ability of starch granules to swell before their physical breakdown [39]. Peak viscosities are directly linked to damage and lower damages result in lower peak viscosities [40], [41]. High peak viscosity indicates high starch content which also relate to water binding capacity of starch [42]. The results (Table I) showed that Tangayoka recorded fairly high starch content of $62.77 \%$. Rosenthal et al. [43] suggested that high peak viscosity contributes to good texture of paste, which basically depends on high viscosity and moderately high gel strength. The relatively high peak viscosity exhibited by most of the cassava varieties in this study suggest that flours from these cassava varieties may be suitable for products requiring high elasticity and gel strength.

The viscosity at $95^{\circ} \mathrm{C}$ measures the ease of cooking of the sample by the amylograph. A low viscosity at $95{ }^{\circ} \mathrm{C}$ is reported to be indicative of how the sample will be difficult to cook [33]. The relatively high viscosities of these cassava varieties at $95{ }^{\circ} \mathrm{C}$ suggest that these cassava varieties would be relatively easier to cook compared to Nalumino, Bangweulu and Chila $\mathrm{B}$ which recorded low viscosities of below $460 \mathrm{BU}$ at $95^{\circ} \mathrm{C}$. No significant differences $(\mathrm{p}<0.05)$ were noted in viscosities at $95{ }^{\circ} \mathrm{C}$ among the studied cassava varieties (Table III).

The viscosity after holding the temperature of the sample constant at $95{ }^{\circ} \mathrm{C}$ for $30 \mathrm{~min}$ indicates the easiness of breakdown of the cooked sample and this shows the cooked stability of the sample [10]. During the hold period there is further disruption of the starch granules and amylose molecules generally leach out into the solution and align in the direction of the shear [9]. Significant differences $(p<0.05)$ were seen in the viscosity of the different cassava varieties at $95{ }^{\circ} \mathrm{C}$-hold. A gradual decrease of the paste viscosity during the hold period indicates thermal breakdown of starch and, thus, may be considered a measure of stability. This period is sometimes called shear thinning, holding strength, hot paste viscosity, or trough, due to the accompanied breakdown in viscosity [9].

Viscosity at $50{ }^{\circ} \mathrm{C}$ indicates the gelation ability of the cooked paste and this reflects the eating consistency of the product [33]. An increased retrogradation property of the paste can be attributed to the strong propensity of hydrogen bond between the hydroxyl groups in the starch structure [20]. Significant differences $(\mathrm{p}<0.05)$ were noted in viscosity at $50^{\circ} \mathrm{C}$ among the cassava varieties (Table III). The viscosity at $50^{\circ} \mathrm{C}$-hold measures the paste stability as it is used in products. Significant differences $(p<0.05)$ were found in the viscosities at $50{ }^{\circ} \mathrm{C}$ and $50{ }^{\circ} \mathrm{C}$-hold for all the cassava varieties.

Breakdown viscosity relates to the stability of the starch during heating [24]. Findings from the breakdown viscosities suggested that these varieties (i.e., Mweru, Chila B, Kampolombo and Tanganyika) are very stable during heating. Afoakwa et al. [24] explained that setback is the measure of the paste hardening on cooling and a stage where retrogradation of starch molecules occurs. Adeyemi and Idowu [44] reported that a high setback value indicates lower retrogradation tendency during cooling and the lower the staling rate of the product made from the flour. Oduro et al. [45] explained that high setback value is valuable for flours to be used for the processing of products such as $f u f u$, which requires high viscosity and paste stability at low temperatures. The observed setback value indicated that Chila A recovered most of its amylose content during cooling than all the other studied varieties. Tangayoka recording the least setback value indicates that the flour gives a noncohesive paste [27]. This means that such flours cannot be used for the processing of foods requiring starch stability at low temperatures such as adhesives and fillings. 


\section{Pasting Characteristics of the Different Cassava Varieties}

Table II shows that Tanganyika recorded the highest pasting temperature $\left(67.6{ }^{\circ} \mathrm{C}\right)$, peak viscosity (595 BU), viscosity at $95{ }^{\circ} \mathrm{C}(592 \mathrm{BU})$ and viscosity at $95^{\circ} \mathrm{C}$-hold $(317$ $\mathrm{BU})$. These suggest that flour from Tanganyika would have high cooking temperature and time profile and may be suitable for foods that require high elasticity and gel strength, easier to cook and also more stable during cooking/preparation such as fufu (pounded cassava) and cassava flour meant for mixing cereals for the preparation of products such as banku or Nshima (Thick maize gruels consumed in West and South-eastern Africa respectively). Chila A registered the highest setback value of 4 BU suggesting that Chila A could be used for products which requires high viscosity and paste stability at low temperature and would be suitable for use as fillers and binders or as substitutes for wheat flour in the baking, and confectionery industries. Tanganyika recorded the least setback (-100 BU) suggesting that flour from Tanganyika cannot be used for products requiring good starch stability at low temperatures, i.e. for example adhesives, fillings and products for refrigeration. Chila $\mathrm{B}$ recorded the lowest values in all the viscoelastic properties with the exception of pasting temperature and setback value. These suggest that Chila B would not be suitable for products that require high viscosity and paste stability such as fufu (pounded cassava) or Nshima, as well as flours for industrial uses such as adhesives, fillings, and binders. However, it would be suitable for household food uses such as snacks where the roots are boiled, roasted, or toasted and consumed

D. Cluster and Principal Component Analyses for Biochemical Composition and Viscoelastic Properties of Cassava Varieties

Bangweulu, Mweulu, Mweru, Manyokola, Nalumino, Kampolombo and Chila A (Cluster A) were different from Chila B (Cluster B) and Tanganyika (Cluster C) on the basis of their pasting properties such as peak viscosity, viscosity at $95^{\circ} \mathrm{C}$, breakdown and setback viscosity. These suggest that the seven local and improved cassava varieties forming Cluster A have similar biochemical and viscoelastic characteristics and would all be suitable for all basic household cassava based food products such as boiled cassava, pounded cassava and roasted cassava grits (gari).

\section{CONCLUSIONS}

The biochemical composition and viscoelastic properties varied with all the cassava varieties studied. The starch content of all the studied cassava varieties was below $80 \%$. Mweru, Tanganyika, Mweulu, and Bangweulu had fairly high starch content $(>60 \%)$ and could be employed in industrial products such as starches, alcohol and glucose. Tanganyika recorded the highest pasting temperature $\left(67.6{ }^{\circ} \mathrm{C}\right)$, peak viscosity $(595 \mathrm{BU})$, viscosity at $95{ }^{\circ} \mathrm{C}(592$ $\mathrm{BU})$ and viscosity at $95^{\circ} \mathrm{C}$-hold (317 BU). These suggest that flour from Tanganyika would have high cooking temperature and time profile and may be suitable for products that require high elasticity and gel strength, easier to cook and also more stable during cooking/preparation such as fufu (pounded cassava) and cassava flour meant for mixing cereals for the preparation of products such as banku or Nshima (Thick maize gruels consumed in West and South-eastern Africa respectively). Chila A registered the highest setback value of 4 BU suggesting that Chila A could be used for products which requires high paste stability and viscosity at low temperatures and would be suitable for use as fillers and binders in the baking and confectionery industries. Tanganyika recorded the least setback (-100 BU) suggesting that flour from Tanganyika cannot be used for products that requires high starch stability at low temperatures, such as adhesives, fillings and products that require refrigeration. Chila B recorded the lowest values in all the viscoelastic properties with the exception of pasting temperature and setback value. These suggest that Chila B would not be suitable for products which require high viscosity and paste stability such as fufu (pounded cassava) or Nshima, as well as flours for industrial uses such as adhesives, fillings, and binders. However, it would be suitable for household food uses such as snacks where the roots are boiled, roasted, or toasted and consumed. Bangweulu, Mweulu, Mweru, Manyokola, Nalumino, Kampolombo and Chila A (Cluster A) were different from Chila B (Cluster B) and Tanganyika (Cluster C) on the basis of their pasting properties such as peak viscosity, viscosity at $95^{\circ} \mathrm{C}$, breakdown and setback viscosity. These suggest that the seven local and improved cassava varieties forming Cluster A have similar biochemical and viscoelastic characteristics and would all be suitable for all basic household cassava-based food products. The differences noted in the viscoelastic properties suggest that different cassava varieties could be predicted for use in different food and industrial products largely due to their varied viscoelastic and pasting properties.

\section{REFERENCES}

[1] Szyniszewska, A. M. Cassava Map, a fine-resolution disaggregation of cassava production and harvested area in Africa in 2014. Scientific Data, 2020, 7: 159.

[2] Aryee, F. N. A., Oduro, I., Ellis, W. O., Afuakwa, J. J. The physicochemical properties of flour samples from the roots of 31 varieties of cassava. Food Contr. 2006, 17, 916-922.

[3] Chiwona-Karltun, L., T. Tylleskar, J. Mkumbira, M. Gebre-Medhin, H Rosling. Low dietary cyanogen exposure from frequent consumption of potentially toxic cassava in Malawi. Int. J. Food Sci. Nutr. 2000, 51, 33-43.

[4] Kolawole, P.O., Agbetoye, L. Ogunlowo, S.A. Sustaining world food security with improved cassava processing technology: the Nigerian experience. Sustainability, 2010, 2, 3681-3694.

[5] El-Sharkawy, M. A. Cassava biology and physiology. Plant Mol. Biol. 2003, 53, 621-641

[6] Baguma, Y., Sun, C., Borén, M., Olsson, H., Rosenquist, S., Mutisya, $\mathrm{J}$., et al. Sugar-mediated semidian oscillation of gene expression in the cassava storage root regulates starch synthesis. Plant Signal Behav. 2008, 3, 1-7.

[7] Otekunrin, O.A. Sawicka, B. Cassava, A 21st Century Staple Crop: How can Nigeria Harness its Enormous Trade Potentials?. Acta Scientific Agriculture, 2019, 3: 194-202.

[8] Chiwona-Karltun, L., J. Mkumbira, J. Saka, M. Bovin, N. Mahungu, R Rosling. The importance of being bitter - a qualitative study on cassava cultivar preference in Malawi. Ecol. Food Nutr. 1998, 37: 219-245.

[9] Maziya-Dixon, B., Adebowale, A. A., Onabanjo, O. O., Dixon, A. G $\mathrm{O}$. Effect of variety and drying methods on physico-chemical properties of high quality cassava flour from yellow cassava roots. African Crop Science Conference Proceedings, 2005, 7, 635-641.

[10] Maziya-Dixon, B., Dixon, A. G. O., Adebowale, A. A. Targeting different end uses of cassava: Genotypic variations for cyanogenic 
potentials and pasting properties. Int. J. Food Sci. Techn. 2007, 42, 969 976.

[11] Montagnac, J. A., Davis, C. R., Tanumihardjo, S. A. Nutritional value of cassava for use as a staple food and recent advances for improvement. Compre. Rev. Food Sci. Food Safety, 2009, 8, 181-188.

[12] Alene, A., Khatazu. Economic impacts of cassava research and extension in Malawi and Zambia. J. Develop. Agric. Econ. 2013, 5 , 457-469.

[13] Bayitse, R., Tornyie, F. \& Bjerre, A-B. Cassava cultivation, processing and potential uses in ghana. In: Handbook on Cassava.Clarissa Klein (Ed). Nova Science Publishers Inc., 2017, USA.

[14] Haggblade, S., Djurfeldt, A. A., Nyirenda, D. B., Lodin, J. B., Brimer, L., Chiona, M. M. et al. Cassava commercialisation in Southeastern Africa. J. Agribusiness Develop. Emer. Econ. 2012, 2, 4-40.

[15] Eleazu, C., K. Eleazu. Determination of the proximate composition, total carotenoid, reducing sugars and residual cyanide levels of flours of six new yellow and white cassava (Manihot esculenta Crantz) varieties. Amer. J. Food Tech. 2012, 7: 642-649.

[16] Gil, J. L., Buitrago, A. J. A. La yuca en la alimentacion animal. In: Ospina B, Ceballos H. (Eds.). La yuca en el tercer milenio: sistemas modernos de produccion, procesamiento, utilizacion $\mathrm{y}$ comercializacion. Cali, Colombia: Centro Internacional de Agricultura Tropical, 2002, 527-569. Retrieved from: http://www.clayuca.org/PDF/libro_yuca/capitulo28. pdf. Accessed on May 24, 2010.

[17] Tewe, O. O., Lutaladio, N. Cassava for livestock feed in sub-Saharan Africa. Rome, Italy: FAO. 2004.

[18] Rawel, H. M., Kroll, J. Die Bedeutung von Cassava ( Manihot esculenta, Crantz) als Hauptnahrungsmittel in tropischen Landern. Deutsche Lebensmittel-Rundschau, 2003, 99, 102-110.

[19] Chandrasekara A. and Kumar, T.J. Roots and Tuber Crops as Functional Foods: A Review on Phytochemical Constituents and Their Potential Health Benefits. International Journal of Food Science. 2016

[20] Afoakwa, E. O., Sefa-Dedeh, S. Viscoelastic properties and changes in pasting characteristics of trifoliate yam (Dioscorea dumetorum) starch after harvest. Food Chem. 2002, 77, 203-208.

[21] Afoakwa, E. O., Adjonu, R., Asomaning, J. Viscoelastic properties and pasting characteristics of fermented maize: influence of the addition of malted cereals. Int. J. Food Sci. Techn. 2010, 45, 380-386.

[22] Iwe, M. O., Wolters, T., Gort, G., Stolp, W., Van Zuilichem, D. J. Behaviour of gelatinization and viscosity in soy-sweet potato mixtures by single-screw extrusion: A response surface analysis. J. Food Eng. 1999, 38, 369-379.

[23] Awoyale, W., Adebayo B. Abass, A.B., Ndavi, M. Maziya-Dixon, B and Sulyok, M. Assessment of the potential industrial applications of commercial dried cassava products in Nigeria. Food Measure. 2017, $11,598-609$.

[24] Afoakwa, E. O., Budu, A. S., Asiedu, C., Chiwona-Karltun, L., Nyirenda, D. B. Viscoelastic properties and physico-functional characterization of six high yielding cassava mosaic disease-resistant cassava (Manihot esculenta Crantz) genotypes. J. Nutr. Food Sci. 2012, 2, 129-137.

[25] Defloor, I., Leijskens, R., Bokanga, M., Delcour, J. A. Impact of genotype and crop age on the bread making and physico-chemical properties of flour produced from cassava (Manihot esculenta Crantz) planted in the dry season. J. Sci. Food Agric. 1994, 66, 193-202.

[26] Adeyemi, I. A., Omolayo, O. Utilization of cocoyam flour and starch for biscuit and cake making. Nigerian J. Sci. 1984, 18, 34-37.

[27] Kim, Y. S., Wiesenborn, D. P., Orr, P. H., Grant, L. A. Screening potato starch for novel properties using differential scanning calorimetry. $J$. Food Sci. 1995, 60, 1060-1065.

[28] Nanda, S. K., Sajeev, M. S., Sheriff, J. T., Hermasankari, P. Starch extraction machinery for tuber crops. Central Tuber Crops Research Institute (Indian Council of Agricultural Research) Sreekariyam, Thiruvananthapuram, Kerala, India. Technical Bull. 2005, 40, 67-78

[29] Pearson, D. The Chemical Analysis of Foods. Sixth edition. J. \& A Churchill, London, 1970.

[30] Champagne, E. T., Bett, K. L., Vinyard, B. T., McClung, A. M., Barton, F. E., et al. Correlation between cooked rice texture and rapid visco analyzer measurements. Cereal Chem. 1999, 76, 764-771.

[31] Padonou, W., Mestres, C. Nago, M. C. The quality of boiled cassava roots: instrumental characterization and relationship with physicochemical properties and sensorial properties. Food Chem. 2005 , 89, 261-270.

[32] Mégnanou, R. M., Kouassi, S. K., Akpa, E. E., Djedji, C., Bony, N., et al. Physicochemical and biochemical characteristics of improved cassava varieties in Cote d'Ivoire. J. Animal and Plant Sci. 2009, 5 , 507-514.

[33] Afoakwa, E. O., Kongor, E. J., Annor, G. A., \& Adjonu, R. Acidification and starch behaviour during co-fermentation of cassava
(Manihot esculenta Crantz) and soybean (Glycine max Merr) into gari, an African fermented food. Int. J. Food Sci. Nutr. 2010, 61, 449-462.

[34] Rasper, V. Theoretical aspests of amylographology. In: The amylograph handbook. Shuey, W. C., Tipples, E. E. (Eds.). America Association of Cereal Chemists, 1980, St Paul, MN, USA

[35] Colonna, P., Leloup, V., Buleon, A. Limiting factors of starch hydrolysis. European Journal of Clinical Nutrition, 1992, 46, 517532.

[36] Emiola, L., Delarosa, L. C. Physicochemical characteristics of yam starches. J. Food Biochem. 1981, 5, 115-130.

[37] Numfor, F. A., Walter, W. M., Schwartz, S. J. Effect of emulsifiers on the physical properties of native and fermented cassava starches. $J$. Agric. Food Chem. 1996, 44, 2595-2599.

[38] Ikegwu, O. J., Nwobasi, V. N., Odoh, M. O., Oledinma, N. U. Evaluation of the pasting and some functional properties of starch isolated from some improved cassava varieties in Nigeria African. $J$. Biotechn. 2009, 8, 2310-2315.

[39] Sanni, L. O., Kosoko, S. B., Adebowale, A. A., Adeoye, R. J. The Influence of palm oil and chemical modification on the pasting and sensory properties of fufu flour. Int. J. Food Prop. 2004, 7, 229-237.

[40] Sanni, L. O., Ikuomola, D. P., Sanni, S. A. Effect of length of fermentation and varieties on the qualities of sweet potato gari. Proceedings of 8th triennial Symposium of the International Society for Tropical Root Crops. Africa Branch (ISTRC-AB), Ed. M.O. Akoroda, IITA, Ibadan, Nigeria, 12-16 November 2001, 208-211.

[41] Oguntunde, A. O. Starch modification for food application: review. Nigerian Food J. 1987, 5, 102-107.

[42] Osungbaro, T. O. Effect of differences in varieties and dry milling of maize on the textural characteristics of Ogi (fermented maize porridge) and Agidi (fermented maize meal). J. Sci. Food Agric. 1990, 52, 1-12.

[43] Rosenthal, F. R. T., Nakamura, T., Espindola, A. M. C., Jochimek, M R. Structure of starch granules. Starke, 1974, 26, 50-55.

[44] Adeyemi, I. A., Idowu, M. A. The evaluation of pregelatinised maize flour in the development of Massai, a baked product. Nigerian Food J. 1990, 8, 63-73

[45] Oduro, I., Ellis, W. O., Dziedzoave, N. T., Nimakoyeboah, K. Quality of gari from selected processing zones in Ghana. Food Contr. 2000, 11 297-303 